\title{
PHOTOELECTROCHEMICAL REDUCTION OF NITRATE IONS ON POROUS SILICON AND DIFFERENT SILICON MODIFIED ELECTRODES
}

\author{
E. C. MUÑOZ ${ }^{*}$, C. A. HEYSER', R. S. SCHREBLER', R. G. HENRÍQUEZI', R. E. MAROTTI². \\ ${ }^{I}$ Instituto de Química, Facultad de Ciencias, Pontificia Universidad Católica de Valparaíso, Casilla 4059, Valparaíso, Chile. \\ ${ }^{2}$ Instituto de Física, Facultad de Ingeniería, Universidad de La República, Herrera y Reissig 565, C.C. 30, 11000 Montevideo, Uruguay
}

(Received: January 26, 2011 - Accepted: June 24, 2011)

\begin{abstract}
We examined the reduction reaction of nitrate ions on different electrode systems: silicon monocrystalline ( $n$-type and $p$-type), porous silicon, and silicon modified by electrodeposited metallic rhenium. In a first stage, voltammetric analysis in different HF media was performed. With this technique it was possible to establish the different processes associated to porous silicon formation. The morphology of the porous silicon was studied using AFM. Voltammetric analysis was then performed using different silicon substrates. This was then used to study the electrochemical reduction reaction of nitrate ions. A decrease in the overpotential of the reaction was observed, with a consequent increase in current density when the silicon electrodes were modified by electrodeposited rhenium. Finally, an analysis of the reaction products from the nitrate electroreduction was carried out using photoelectrolysis at controlled potential.
\end{abstract}

\section{INTRODUCTION}

The presence of nitrogen in vegetables is associated to the nitrogen cycle where plants assimilate inorganic nitrogen in the form of nitrates for use in vegetable-protein synthesis. Nitrates are also found in drinking water, principally due to a natural presence or as a consequence of contamination from agricultural practices (fertilizers and manure). Nitrates are also used as additives in cured meats, due to their bacteriostatic properties and their capacity to fix red color. There are, therefore, three main sources of nitrate ingestion in our diet: vegetables, water and cured meat. Vegetables constitute the most important source of nitrates in the diet, contributing over $80 \%$ of daily ingestion. The principal concerns regarding nitrate presence in food have two aspects: firstly, nitrite toxicity derived from nitrate reduction. This species is capable of oxidizing the hemoglobin in red blood cells, transforming it into methemoglobin ${ }^{1}$. Methemoglobin has difficulty transporting oxygen to the cells. The second concern is that nitrates and nitrites can form $\mathrm{N}$-nitrosoamines and $\mathrm{N}$-nitrosoamides (carcinogenic agents) ${ }^{2}$.

Direct reduction of nitrate ions on metal electrodes has been investigated in order to find a simple and efficient system in the production of substances of interest. In general terms, the bibliography on the nitrate reduction reaction, NRR, is more extensive on the group of noble metals and in particular on Platinum ${ }^{3,4}$. This is mainly due to the electrocatalyst behaviour of Platinum in this reaction, and so it has been used as a model in the study of the catalysis mechanism of the reduction of nitrate and nitrite, both in alkali media and in acids. Studies into the NRR on Pt electrodes have led to the idea that the role of this metal in the catalyzed reaction could be associated to the vacancy offered by the band $d$, making it a metal with a strong capacity to adsorb different intermediate and reactive chemical species ${ }^{5}$. Based on the above, it can be seen that most substrates used in the NRR are metals. There is no information in the literature concerning reducing nitrate on semiconductor electrodes or on modified semiconductor substrates. For this reason, the aim of this paper was to study the nitrogen electroreduction reaction on different semiconductor substrates ( $n$-type and $p$-type silicon) and on different modified semiconductors electrodes: $\mathrm{n}$ and $\mathrm{p}$ porous silicon, silicon/rhenium, and porous silicon/rhenium.

\section{EXPERIMENTAL SECTION}

The substrates used were monocrystalline $p$-type Silicon(100) with a resistivity between $0.01-0.3 \Omega \mathrm{cm}\left(N_{a} \cong 5 \times 10^{17} \mathrm{~cm}^{-3}\right)$, B-doped, polished/ etched surfaces, and monocrystalline $n$-type Silicon $(100)$ with a resistivity between $1.3-1.7 \Omega \mathrm{cm}\left(N_{\mathrm{d}} \cong 3 \times 10^{15} \mathrm{~cm}^{-3}\right)$, P-doped, polished/etched surfaces (Int. Wafer Service, CA, USA). The silicon wafers were cut into rectangles (1.0 $\left.\times 2.5 \mathrm{~cm}^{2}\right)$ and treated in accordance with previously used procedures ${ }^{1,6,7,8,9}$.
The silicon area exposed to the solution was $1.0 \mathrm{~cm}^{2}$. Before each experiment, the electrode surface was etched again for $2 \mathrm{~min}$ in $4 \% \mathrm{HF}$ solution and finally the substrates were washed thoroughly with deionized water. For each measurement, a new electrode of $p-\operatorname{Si}(100)$ was used, as some metals can diffuse into the silicon ${ }^{10,11}$. Ohmic contact was made with eutectic InGa on the etched face that is not exposed to the electrolytic solution and the electrodes were mounted on a Teflon support. The electrolyte solutions were prepared with double distilled and deionized water (Millipore) with an electrical resistivity of $18 \mathrm{M} \Omega \mathrm{cm}$. The reagents used were analytical grade Fluka $\left(\mathrm{NH}_{4} \mathrm{ReO}\right)$ and Merck ( $\left.\mathrm{HF}, \mathrm{NaNO}_{3}, \mathrm{H}_{2} \mathrm{SO}_{4}\right)$. A pure argon stream was passed through the solution for $30 \mathrm{~min}$ before measurement, and over the solution during the experiments. The formation of porous Silicon (PS) was carried out through a galvanostatic technique using a Teflon electrochemical cell with a plastic optical pass and a two electrode arrangement. The working electrodes were $n$-type and $p$-type silicon with a platinum wire as counter electrode. For the $n$-type substrate, a starting current of $10 \mathrm{~mA} \mathrm{~cm}{ }^{-2}$ for $300 \mathrm{~s}$ under illumination conditions was applied in a $4 \% \mathrm{HF}$ in a $50 \%$ ethanol solution. For the $p$-type substrate, PS was done by applying $10 \mathrm{~mA} \mathrm{~cm}^{-2}$ for $3600 \mathrm{~s}$ under darkness conditions in a $4 \% \mathrm{HF}$ in a $50 \%$ ethanol solution. The formation of the silicon/rhenium electrode system was performed using a chronoamperometric technique. These last experiments were stopped after the constant total cathodic charge passed $0.2 \mathrm{C} \mathrm{cm}^{-2}$. For the electrochemical reduction of nitrate ions on the different modified semiconductor substrates, an aqueous solution of 0.1 $\mathrm{M} \mathrm{NaNO}_{3}$ at $\mathrm{pH}=2$ was used at room temperature and a scan rate of 0.010 $\mathrm{V} / \mathrm{s}$. The electrochemical cell in this case was a conventional three electrode cell consisting of a platinum wire as counter electrode and a mercury/mercury sulfate electrode (MSE) $\left(\mathrm{Hg} / \mathrm{Hg}_{2} \mathrm{SO}_{4}, \mathrm{~K}_{2} \mathrm{SO}_{4}\right.$ (saturated), $0.640 \mathrm{~V}$ vs. SHE) was used as reference electrode. All the potentials reported in this study refer to this reference electrode. All the electrochemical measurements (galvanostatic/ potentiostatic) were taken using Princeton Applied Research (PAR) model 273 A equipment, attached to a computer. Illumination was achieved with a xenon lamp of 75 Watts (Oriel Instruments 6263) mounted in a lamp holder (Oriel 66902) and using a water filter (Oriel 61945) and a $1 \mathrm{~m}$ length optical fiber (Oriel 77578). A power supply of $40-200$ watts (Oriel 68907) was used to generate the arc in the lamp. The illumination power was quantified inside the cell by means of a power meter (Oriel 70260). The samples illuminated with the Xe lamp reached a light intensity of $4.0 \mathrm{~mW} \mathrm{~cm}{ }^{-2}$. Photoelectrolysis was performed at controlled potential in order to determine the reaction products in the reduction of nitrate ions. The modified $p$-Si/Re electrode was immersed in approximately $100 \mathrm{ppm}$ of $\mathrm{NaNO}_{3}(\mathrm{pH} 2)$ solution and a constant potential of $-0.8 \mathrm{~V}$ was set. During the experiment, the sample was illuminated using the solar simulator. Samples were extracted from the cell at 5-30-60 and 120 min. Each experiment began with fresh $\mathrm{NaNO}_{3}$ solution. The reaction 
products analyzed were: $\mathrm{NO}_{3}^{-}, \mathrm{HNO}_{2}$, and $\mathrm{NH}_{4}^{+}$. They were quantified by the following analytic techniques: (i) $\mathrm{NO}_{3}^{-}$ions were complexed with resorcine and indophenol red-violet colorant, and then determined photometrically by NOVA60 (275 nm); (ii) $\mathrm{NO}_{2}{ }^{-}$species were complexed by the addition of sulfonamide and naphtylethyldiamine hydrochloride, considering standard method $4500-\mathrm{NO}_{2} \mathrm{~B}$, and determinated photometrically by NOVA60 (543 $\mathrm{nm}$ ); (iii) for determination of $\mathrm{NH}_{4}^{+}$ions, hypochlorite was added at $\mathrm{pH}>8$, to obtain monochloramine which forms a derivative of blue-indophenol with the addition of a substituted phenol. This was determined photometrically by NOVA60 $(630 \mathrm{~nm})$. An analogue procedure at EPA350 was performed using standard method 4500- $\mathrm{NH}_{3} \mathrm{D}$ and ISO 7150/1. The AFM images were obtained with a Digital Instrument Nanoscope IIIa series, employed in tapping mode at a scan rate of $0.02 \mu / \mathrm{s}$. Tips of silicon nitride, model Olympus AC240TS from Asylum Research with a resonance frequency between $200-400 \mathrm{kHz}$ and a radius of curvature of 5 to $10 \mathrm{n} \mu$ were also used. All samples used for ex situ AFM were prepared in the electrochemical cell.

\section{RESULTS AND DISCUSSION}

Synthesis of PS from crystalline $\boldsymbol{n}$-Si and $\boldsymbol{p}$-Si electrodes by means of galvanostatic pulses

For the PS formation it was necessary to analyze the experimental conditions, principally current density and time. Figures 1 (a) and 1(b) show potentiodynamic $j / E$ profiles of the $p$ - $\mathrm{Si}(100)$ and $n$-Si(100) electrodes, respectively, immersed in $0.4 \% \mathrm{HF}$. The $j / E$ profile for the $n$-Si/HF system was done under illumination conditions for hole photogeneration. In Figure 1(c), the $p$-Si electrode was immersed in HF solution at different concentrations: $4 \%, 10 \%$ and $20 \% \mathrm{w} / \mathrm{w}$.

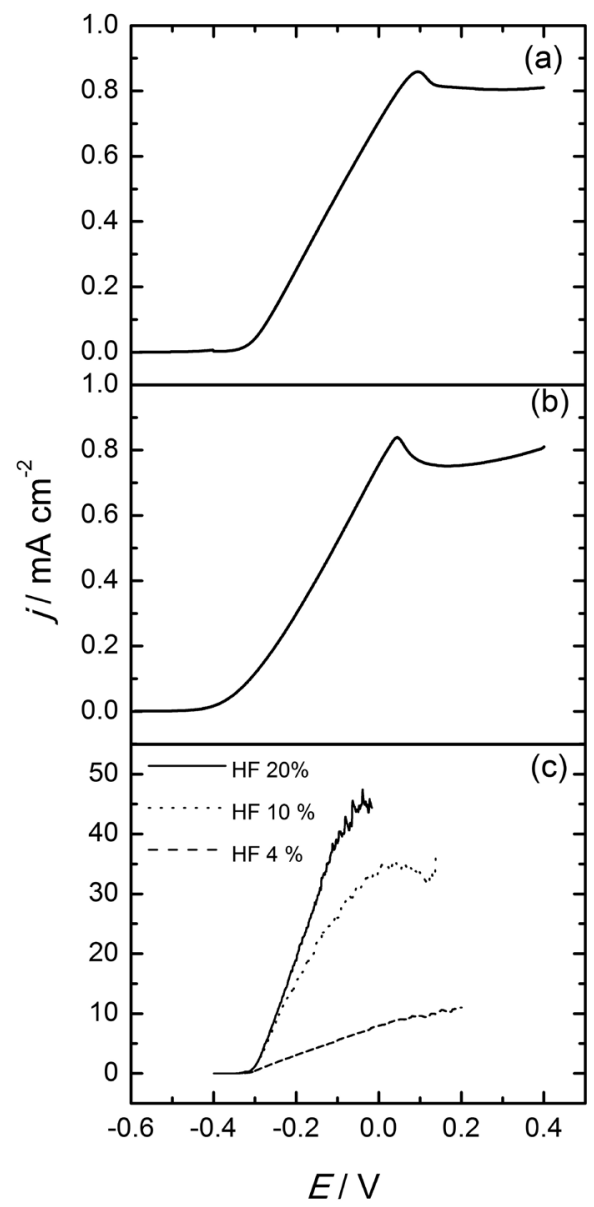

Figure 1. Potentiodynamic $j / E$ profiles of: (a) $p$-Si(100) electrode in HF $0.4 \% \mathrm{w} / \mathrm{w}$; (b) $n$-Si(100) in HF $0.4 \% \mathrm{w} / \mathrm{w}$; (c) $p$-Si(100) in solutions at different HF concentrations: $4 \% \mathrm{w} / \mathrm{w}$ HF; $10 \% \mathrm{w} / \mathrm{w} \mathrm{HF} ; 20 \% \mathrm{w} / \mathrm{w}$ HF. Scan rate: 0.01 $\mathrm{V} \mathrm{s}^{-1}$.
In Figure 1 it is possible to observe that in $0.4 \% \mathrm{HF}$ solution there are two zones for both silicon susbtrates which are attributed to the formation of different structures on the silicon surface. The first zone is from about $0.3 \mathrm{~V}$ until the current maximum value -in $0.1 \mathrm{~V}$ for the $p$-Si and between $-0.4 \mathrm{~V}$ to $0.05 \mathrm{~V}$ for $n$-Si substrate. This zone has been attributed to the PS formation ${ }^{12}$. From this zone and towards more positive potential values, an electropolishing of the silicon surface is produced which corresponds to the active dissolution of the semiconductor material. Considering the PS formation on $p$-Si, the best results were obtained when the following experimental conditions were applied: $10 \mathrm{~mA} \mathrm{~cm}^{-2}$ current density, $4 \% \mathrm{HF}$ in a $50 \%$ ethanol solution and at a time of $3600 \mathrm{~s}$. Ethanol is basically used to reduce the surface tension of the electrolytic mixture as surface wetting is important for good pore uniformity ${ }^{13}$. The potential transient obtained (not shown) reached a stationary value of $0.5 \mathrm{~V}$ which is in agreement with the zone associated with the formation and growth of PS before the electropolishing region in Figure $1^{14}$. PS on the $n$-Si substrate was carried out under illumination, which is necessary for hole generation in the valence band and also for the oxidation process. For this substrate the best results were attained with a current density of $10 \mathrm{~mA} \mathrm{~cm}-2$ in a $4 \%$ $\mathrm{HF} / 50 \%$ ethanol solution applied for $300 \mathrm{~s}$. The same behavior was observed in the obtained potential transient (not shown). A potential of about $0.5 \mathrm{~V}$ was reached on the interface, which is in agreement with the potential formation of PS. Under similar experimental conditions for PS formation, Labunov et al. ${ }^{14}$ postulated the following mechanism for both substrates.

$$
\begin{gathered}
\mathrm{Si}_{(\mathrm{s})}+2 \mathrm{HF}_{\text {(aq) }} \rightarrow \mathrm{SiF}_{2(\mathrm{~s})}+\mathrm{H}_{2(\mathrm{~g})} \\
2 \mathrm{SiF}_{2(\mathrm{~s})} \rightarrow \mathrm{Si}_{\text {amorphous }}+\mathrm{SiF}_{4(\mathrm{aq})} \\
\mathrm{SiF}_{4(\mathrm{aq})}+2 \mathrm{HF}_{\text {(aq) }} \rightarrow \mathrm{H}_{2} \mathrm{SiF}_{6(\mathrm{aq})} \\
\mathrm{SiF}_{2 \text { (aq) }}+2 \mathrm{H}_{2} \mathrm{O}_{(\mathrm{l})} \rightarrow \mathrm{SiO}_{2(\mathrm{aq})}+2 \mathrm{HF}_{(\mathrm{aq})}+\mathrm{H}_{2(\mathrm{~g})} \\
\mathrm{SiO}_{2(\mathrm{aq})}+4 \mathrm{HF}_{\text {(aq) }} \rightarrow \mathrm{SiF}_{4(\mathrm{aq})}+2 \mathrm{H}_{2} \mathrm{O}_{(\mathrm{l})} \\
\mathrm{SiF}_{4(\mathrm{aq})}+2 \mathrm{HF}_{\text {(aq) }} \rightarrow \mathrm{H}_{2} \mathrm{SiF}_{6(\text { (aq) }}
\end{gathered}
$$

Reactions (1), (2) and (3) occur simultaneously, and it has been reported that reactions (1) and (2) are favored in the porous silicon formation process, and reaction (3) is less favored. Reaction (1) occurs on the silicon surface when an electrical current is applied to the silicon. This reaction seems to appear between $25-40$ seconds. Furthermore, the low conductivity of the $\mathrm{SiF}_{2}$ film helps its partial dissolution and this initiates reactions (2) and (3), which appear simultaneously. When reaction (2) starts porous formation also begins, and with the initiation of the reaction (3), which implies the total dissolution of the $\mathrm{SiF}_{2}$ layer, porous growth occurs. The latter process is dependent on the fluoride ion concentration, as well as other factors. According to the authors, the $\mathrm{F}^{-}$ion concentration decreases slightly inside the pore and this affects reactions (2) and (3). This fact is a feature of processes with a rate determinant step characterized by $\mathrm{F}^{-}$ion diffusion to the solid/dissolution interface.

In Figure 2, real images of PS samples ( $p$-type and $n$-type) under UV radiation are shown. These samples were obtained under the aforementioned conditions. It is possible to observe the photoluminescent behavior of PS which has been reported by other authors ${ }^{15,16,17}$.

Morphological analysis by atomic force microscopy (AFM) and scanning electron microscopy (SEM)

Figure 3a shows a $10 \times 10 \mathrm{~mm}$ AFM image of a bare $p$-Si(100) substrate after the surface treatment described in the previous section. Figures $3 \mathrm{~b}$ and $3 \mathrm{c}$ show $0.5 \times 0.5 \mu \mathrm{m}$ and $2 \times 2 \mu \mathrm{m}$ ex situ AFM images for $p$-PS formed at $10 \mathrm{~mA}$ $\mathrm{cm}^{-2}$ current density, $4 \% \mathrm{HF}$ in a $50 \%$ ethanol solution during $3600 \mathrm{~s}$. 


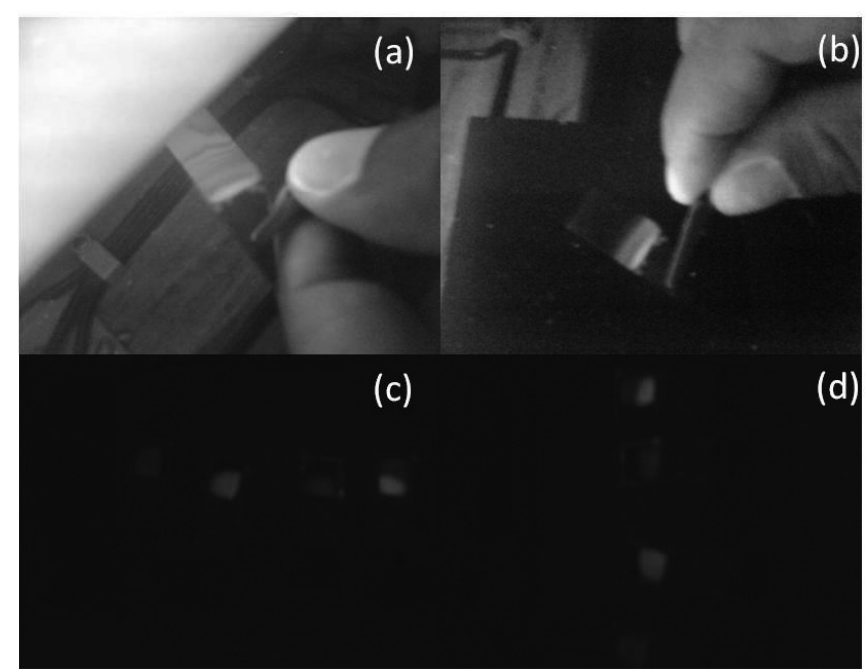

Figure 2. Real images of PS under UV light: (a) and (c) $p$-PS formed under a $10 \mathrm{~mA} \mathrm{~cm}^{-2}$ current density, $4 \% \mathrm{HF}$ in a $50 \%$ ethanol solution and at a time of $3600 \mathrm{~s}$.; (b) and (d) $n$-PS formed under a $10 \mathrm{~mA} \mathrm{~cm}^{-2}$ current density, $4 \% \mathrm{HF}$ in a $50 \%$ ethanol solution for $300 \mathrm{~s}$.
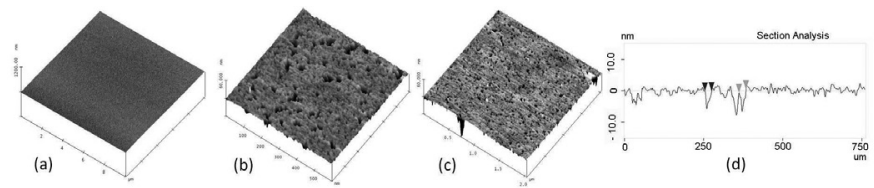

Figure 3: AFM images of (a) bare $p-\operatorname{Si}(100)$; (b) and (c) different zones for $p$-PS formed at $10 \mathrm{~mA} \mathrm{~cm}^{-2}$ current density, $4 \% \mathrm{HF}$ in a $50 \%$ ethanol solution during $3600 \mathrm{~s}$. (d) Section analysis of the surface.

Figure 3a shows a typical morphology of bare silicon: a smooth surface with very low roughness consistent with a polished surface. In Figures 3a and $3 b$, it is possible to observe that under these experimental conditions porous structures are formed without any defined order. From Figure 3d a section analysis allows determination of an average pore diameter at between approximately $20-30 \mathrm{~mm}$. These pore diameters are reported in the literature as a micropore ${ }^{5,14,18,19,20}$

Figure 4 shows the morphological characterization of $n$-type substrates. Figure 4a shows a $10 \times 10 \mathrm{~mm}$ AFM image of a bare $n$-Si(100) substrate after pretreatment. Figures $4 \mathrm{~b}$ and $4 \mathrm{c}$ show $0.3 \times 0.3 \mu \mathrm{m}$ and $0.8 \times 0.8 \mu \mathrm{m}$ ex situ AFM images, for $p$-PS formed at $10 \mathrm{~mA} \mathrm{~cm}^{-2}$ current density, $4 \% \mathrm{HF}$ in a $50 \%$ ethanol solution for $3600 \mathrm{~s}$.
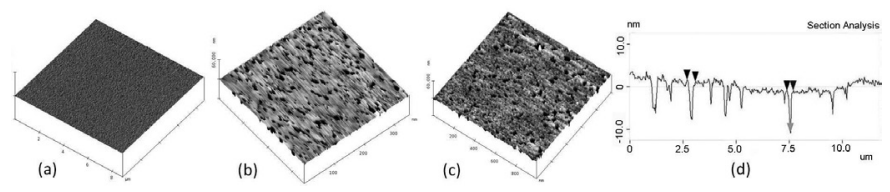

Figure 4: AFM images of (a) bare $n$-Si(100); (b) and (c) different zones for $n$-PS formed at $10 \mathrm{~mA} \mathrm{~cm}^{-2}$ current density, $4 \% \mathrm{HF}$ in a $50 \%$ ethanol solution for $300 \mathrm{~s}$ under illumination. (d) Section analysis of the surface.

The same features as for the $p$-Si samples can be seen in this Figure: a smooth surface for bare silicon and an average pore diameter about $300-400$ $\mathrm{nm}$ for the samples after anodic etching.

Voltammetric study of the reduction reaction of nitrate ions, RRN, on different modified silicon electrodes

The study of RRN on different modified silicon surfaces is shown in Figure 5. The potentiodynamic $j / E$ profiles were obtained from a $0.1 \mathrm{M} \mathrm{NaNO}_{3}(\mathrm{pH}=$ 2 ) solution. The electrodes used in these experiments were: bare $p$-Si(100), bare rhenium, bare $p$-PS, $p$-PS/Re and $p$-Si/Re substrates. The $p$-PS substrate was synthesized with the same experimental conditions mentioned above $(10 \mathrm{~mA}$ $\mathrm{cm}^{-2}$ current density, $4 \% \mathrm{HF}$ in a $50 \%$ ethanol solution for $3600 \mathrm{~s}$ ). Rhenium was chronoamerometrically deposited onto $p$-Si and $p$-PS substrates from a $50 \mathrm{mM} \mathrm{NH}_{4} \mathrm{ReO}_{4}$ in $0.1 \mathrm{M} \mathrm{H}_{2} \mathrm{SO}_{4}$ electrolytic solution at $-0.8 \mathrm{~V}$ until cathodic charge passed $0.2 \mathrm{C}$. The potentiodynamic profiles were recorded from the open circuit potential, OCP, $-0.40 \mathrm{~V}$ to $-1.2 \mathrm{~V}$ and then to the OCP value. All the samples were illuminated with the solar simulator (except Re) for electron photogeneration. No response was observed in darkness conditions.

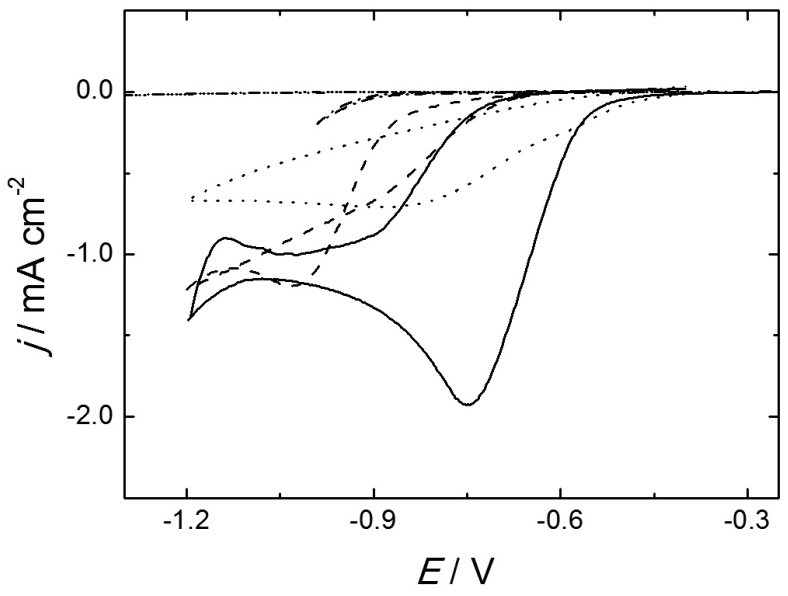

Figure 5: Potentiodynamic $j / E$ profiles of different $p$-type modified silicon

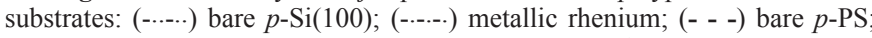
$(\ldots \ldots \ldots . .)$.$p -PS/Re; (\square) p$-Si/Re. Scan rate: $0.01 \mathrm{~V} \mathrm{~s}^{-1}$. Light intensity from solar simulator: $4.0 \mathrm{~mW} \mathrm{~cm}^{-2}$.

A negligible response of bare $p$-Si and metallic rhenium for the RRN can be observed. The modified systems present the best performances for the RRN, however there are some differences. The bare $p$-PS electrode increased the photocurrent for the RRN and shifted the onset potential toward more positive potentials $(-0.64 \mathrm{~V})$. The limiting density photocurrent reached for this electrode at $-1.03 \mathrm{~V}$ was $-1.19 \mathrm{~mA} \mathrm{~cm}{ }^{-2}$. The $p$-PS/Re substrate shifted the onset potential of the RRN toward more positive potentials $(-0.44 \mathrm{~V})$, however the limiting photocurrent decreased to $-0.73 \mathrm{~mA} \mathrm{~cm}-2$ in comparison to the bare $p$-PS electrode though now at $-0.84 \mathrm{~V}$. Finally, the best results were attained by the $p$-Si/Re electrode which showed onset potential at $-0.44 \mathrm{~V}$ and a limiting photocurrent of $-1.92 \mathrm{~mA} \mathrm{~cm}{ }^{-2}$ at $-0.75 \mathrm{~V}$. Therefore, the systems modified by electrodeposited rhenium present two improvements compared to the bare systems. Thermodynamically speaking, the modified systems shift the onset potential of the RRN towards more positive potentials (decreasing the overpotential), and kinetically, the presence of rhenium on the silicon surface rises the RRN rate. The behavior of the $p$ - $\mathrm{Si} / \mathrm{Re}$ interface can be considered as a photoelectrocatalyst.

Moreover, the same study was carried out as described above using $n$-type silicon substrates: bare $n$-Si(100), bare rhenium, bare $n$-PS, $n$-PS/Re and $n$-Si/Re substrates. The $n$-PS substrate was synthesized with the same experimental conditions mentioned above $\left(10 \mathrm{~mA} \mathrm{~cm}{ }^{-2}\right.$ current density, $4 \%$ $\mathrm{HF}$ in a $50 \%$ ethanol solution for $300 \mathrm{~s}$ under illumination). Rhenium was chronoamerometrically deposited onto $n$-Si and $n$-PS substrates from a 50 $\mathrm{mM} \mathrm{NH}_{4} \mathrm{ReO}_{4}$ in $0.1 \mathrm{M} \mathrm{H}_{2} \mathrm{SO}_{4}$ electrolytic solution at $-1.0 \mathrm{~V}$ until the cathodic charge passed $0.2 \mathrm{C}$. The potentiodynamic profiles were recorded from the open circuit potential, OCP, $-0.40 \mathrm{~V}$ to $-1.2 \mathrm{~V}$ and then to the OCP value. All the experiments were carried out in darkness conditions. 


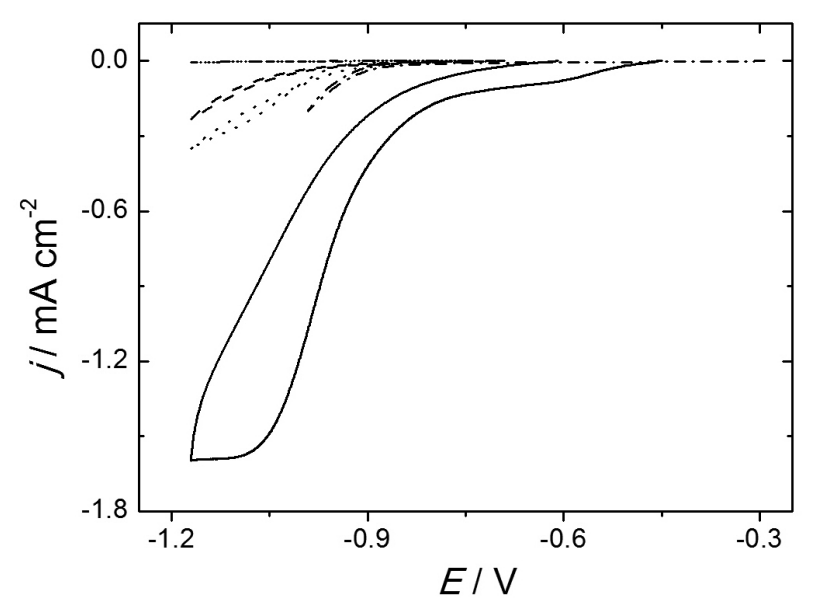

Figure 6: Potentiodynamic $j / E$ profiles of different $n$-type modified silicon substrates: (-.....) bare $n$-Si(100); (-....) metallic rhenium; (- - -) bare $n$-PS $(\cdots \ldots \ldots . .)$.$n -PS/Re; (-) n$-Si/Re. Scan rate: $0.01 \mathrm{~V} \mathrm{~s}^{-1}$ in darkness conditions.

As can be observed there are some differences compared to the results obtained using $p$-type substrates. There appears to be a negligible response for bare $n$-Si. The $n$-PS and $n$-PS/Re modified systems present a slight increase in the current density value and a decrease in the onset potential compared to the bare $n$-Si electrode. However these modified substrates present a higher overpotential than the Re electrode. This means that these modified electrodes decrease the work necessary to carry out the RRN compared with the bare $n$-Si electrode but do not improve the reaction kinetically compared with Re electrode. However, the best results are obtained with the $n$-Si/Re electrode: a decrease in onset potential to $-0.45 \mathrm{~V}$ and an increase in current density of almost one order of magnitude $\left(-1.56 \mathrm{~mA} \mathrm{~cm}^{-2}\right)$. As with the $p$-Si/Re electrode, the $n-\mathrm{Si} / \mathrm{Re}$ system decreases the overpotential value for $\mathrm{RRN}$ and increases the rate of the process. For a better visualization of the best result found using the $p$-Si/Re and $n$-Si/Re electrodes, Figure 7 shows these results for both electrode sy

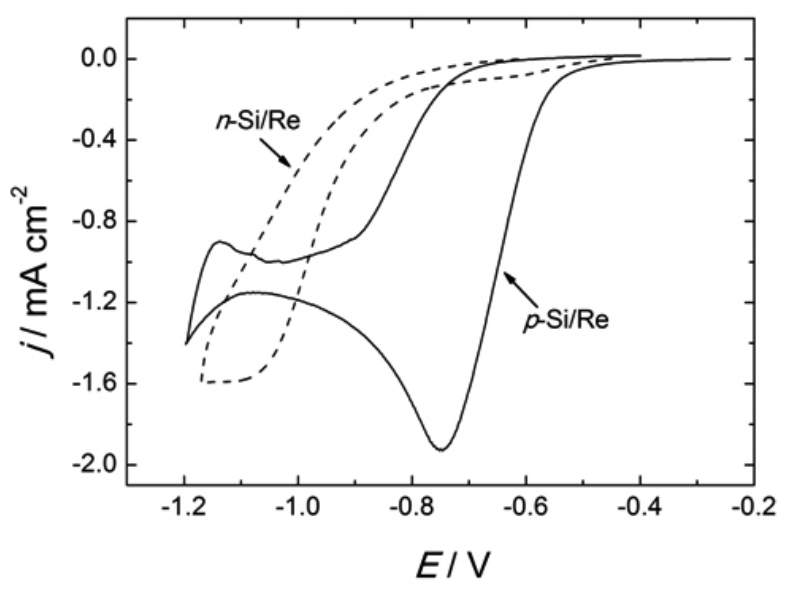

Figure 7: Comparative results of the potentiodynamic $j / E$ profiles corresponding to the RRN on: (-) $p$-Si/Re under illumination; (- - -) $n$-Si/Re in darkness conditions. Scan rate $0.01 \mathrm{~V} \mathrm{~s}^{-1}$.

It can be seen in this Figure that the onset potential for RRN on both electrodes appears approximately at the same potential value $(-0.60 \mathrm{~V})$. However, the $p$-Si/Re electrode presents a higher current for this reaction indicating that the reaction rate on this substrate is higher than on the $n$-Si/Re electrode. The potential value at the limiting current on both electrode systems, $-1.1 \mathrm{~V}$ and $-0.74 \mathrm{~V}$ for the $n-\mathrm{Si} / \mathrm{Re}$ and $p$-Si/Re electrodes respectively, shows a difference of about $0.3 \mathrm{~V}$. Similar behavior has been observed in the copper electrodeposition on $n$-Si and $p$-Si ${ }^{8,9}$, and it can be explained considering the band structures obtained for both semiconductors in these conditions. Approximate band diagrams of both semiconductors are shown in Figure 8.

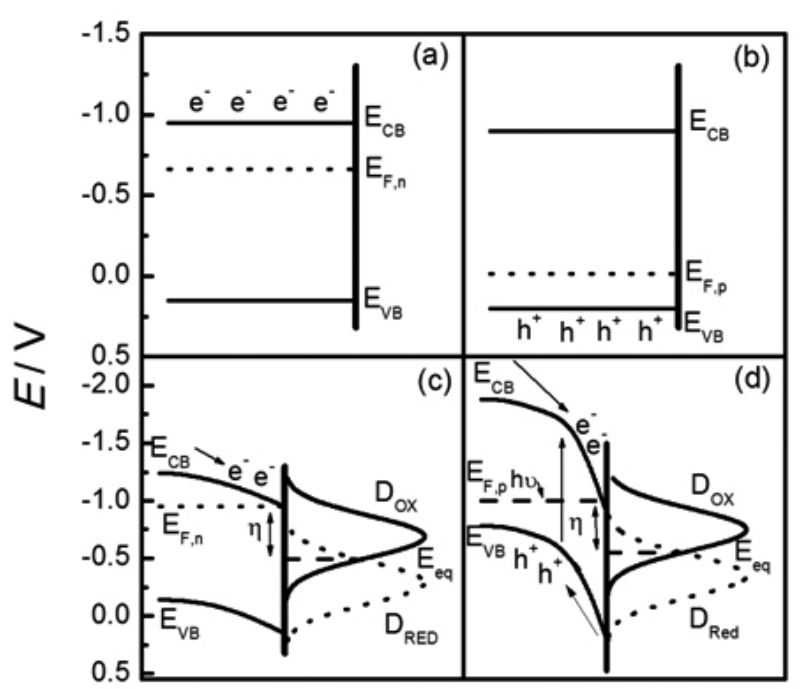

Figure 8: Illustration of the band diagrams for silicon under different conditions: (a) and (b) $n$-Si and $p$-Si under flat band conditions; (c) $n$-Si under forward bias $(-1.0 \mathrm{~V})$, accumulation layer; (d) $p$-Si under illumination and reverse bias $(-1.0 \mathrm{~V})$ depletion layer.

Figure 8 was drawn taking into account the conditions obtained in a $0.1 \mathrm{M}$ $\mathrm{Na}_{2} \mathrm{SO}_{4}$ electrolyte and through electrochemical impedance spectroscopy (data not shown $)^{8,9}$. As can be observed, in these conditions the difference between the Fermi levels (flat band potentials) of $n-\mathrm{Si}(-0.66 \mathrm{~V})$ and $p-\mathrm{Si}(-0.016 \mathrm{~V})$ is approximately $0.6 \mathrm{~V}$. If the same overpotential value $(\eta)$ is applied at both semiconductors substrates, different polarization regimes and band bending are achieved. In fact, on the $p$-Si substrate a stronger electric field can be observed in the space charge layer in comparison with the $n$-Si. A charge particle can move under two influences. One is the concentration gradient, meaning that we return to Fick's law. On the other hand, as particles are changed, they will be influenced by the electric field, the gradient of the potential-distance relation inside the semiconductor ${ }^{\square}$. Thus, under these conditions the electrons photogenerated on the conduction band in $p$-Si will be send faster than on the $n$-Si electrode to the semiconductor/electrolyte interface and with this an increase of the reaction rate must be observed.

Preliminary analysis of reaction products of the photoelectrochemical reduction of nitrate ions

For this experiment, the $p$-Si/Re system was chosen due to the best results reached and photoelectrolysis was performed at controlled potential of $-0.8 \mathrm{~V}$. As was mentioned in the experimental section, a $\mathrm{p}-\mathrm{Si} / \mathrm{Re}$ modified electrode was immersed in approximately $100 \mathrm{ppm} \mathrm{NaNO}_{3}(\mathrm{pH}=2)$. During the experiment, the sample was illuminated using a solar simulator. Samples were extracted from the cell at 5-30-60 and $120 \mathrm{~min}$. Each experiment began with a fresh $\mathrm{NaNO}_{3}$ solution. The reaction products analyzed were: $\mathrm{NO}_{3}^{-}, \mathrm{HNO} 2$, and $\mathrm{NH}_{4}^{+}$. The results obtained are summarized in Table 1.

Table 1: Nitrogen reaction products from controlled potential photoelectrolysis technique.

\begin{tabular}{|c|c|c|c|c|}
\hline Sample & {$\left[\mathbf{N O}_{3}{ }^{-}\right] / \mathbf{p p m}$} & {$\left[\mathbf{N O}_{2}{ }^{-}\right] / \mathbf{p p m}$} & $\begin{array}{c}{\left[\mathbf{N H}_{4}{ }_{4}^{+}\right] /} \\
\mathbf{p p m}\end{array}$ & $\begin{array}{c}\text { Other/ } \\
\mathbf{p p m}\end{array}$ \\
\hline Blank & 112 & $-0-$ & $-0-$ & $-0-$ \\
\hline $\mathbf{5}$ min & 33.6 & 1.232 & 4.48 & 72.7 \\
\hline $\mathbf{3 0}$ min & 30.2 & 1.3 & 5.49 & 75.0 \\
\hline $\mathbf{6 0}$ min & 28.0 & 7.84 & 6.27 & 69.9 \\
\hline $\mathbf{1 2 0}$ min & 25.8 & 9.74 & 7.2 & 69.2 \\
\hline
\end{tabular}

As can be seen in Table 1, all the species were detected by analytical methods. In this context and considering the short experiment time in the photoelectrolysis process, the most important result was the detection of amoniacal-nitrogen, indicating that the electrode system, $p$-Si/Re, can adsorb the nitrogen intermediates and transform them down to N(3-). However, we need to continue research into this area due to the large amount of other reaction products, which could be indicative of the presence of nitrogen gas. The experiment must also be carried out for longer periods of time. 


\section{CONCLUSIONS}

According to the results, we were able to synthesize a porous structure, producing a photoluminiscent material under UV irradiation. Additionally, both PS present a better performance toward the RRN compared to bare $n$-Si and $p$-Si. The presence of rhenium on the Si surface ( $n$-type and $p$-type) produced a decrease in the overpotential of the reduction reaction of $\mathrm{NO}_{3}^{-}$ ions and an increase in the current density of the process, thus presenting photoelectrocatalyst and electrocatalyst characteristics for this reaction considering the $p$-Si/Re and $n-\mathrm{Si} / \mathrm{Re}$ electrode, respectively. This effect has been described by considering the multiple nature of the interface, i.e. a Semiconductor/metal/electrolyte interface. The semiconductor acts as a source of electrons (or photogenerated electrons) transferring them to the metal islands where they become electrocatalysts of the reduction reaction. Finally, electrons on the metallic islands are transferred to the ions in solution at higher rates than in the absence of the islands. This effect has been attributed to the band modulation produced by the presence of metal deposits on semiconductors. The analysis of the reaction products by photoelectrolysis at controlled potential gives encouraging information, leading to the conclusion that the formation of $\mathrm{N}_{2}$ through the $p$-Si/Re interface may be possible; this in turn will be a source of ideas for future research.

\section{ACKNOWLEDGMENT}

We would like to thank FONDECYT, Chile, for financial support for this research (grant $\mathrm{N}^{\circ} 11060514$ and 7080186) and the Dirección de Investigación e Innovación of the Pontificia Universidad Católica de Valparaíso (grant $\mathrm{N}^{\circ}$ 037.208/2008 DII-PUCV). E. Muñoz and R. Henríquez acknowledge the Programa Bicentenario de Ciencia y Tecnología, PSD82. R. Marotti also acknowledges support received from PEDECIBA - Física, and the CSIC (Comisión Sectorial de Investigación Cientifica) of the Universidad de la República, in Montevideo, Uruguay.

\section{REFERENCES}

1.- $\quad$ E. Muñoz, R. Schrebler, R. Henríquez, C. Heyser, P. Verdugo, R. Marotti, Thin Solid Films 518, 138, (2009).

2.- K.P. Cantor, Cancer Causes Control Pap. 8, 292, (1997).

3.- G. Ritzoulis, J. Electroanal. Chem. 327, 209, (1992).

4.- A. Ahmadi, E. Bracey, R. Wyn Evans, G. Attard, J. Electroanal. Chem. 350, 297, (1993).
5.- $\quad$ L. D. Burke, W. A. O'Leary, J. Appl. Electrochem. 19, 758, (1989).

6.- E. Muñoz, R. Schrebler, M. Orellana, R. Córdova, J. Electroanal. Chem. 611, 35, (2007).

7.- $\quad$ E. Muñoz, R. Schrebler, P. Grez, R. Henríquez, C. Heyser, P. Verdugo, R. Marotti, J. Electroanal. Chem. 633, 113, (2009).

8.- E. C. Muñoz, R. S. Schrebler, P. K. Cury, C. A. Suárez, C. H. Gómez, R. A. Córdova, E. A. Dalchiele, R. E. Marotti, J. Phys. Chem. B 110, 21109, (2006).

9.- E. C. Muñoz, R. Schrebler, R. Córdova, R. Marotti, E. Dalchiele, J. Phys. Chem. B 111, 16505, (2007).

10.- G. Oskam, P.M. Vereecken, P.C. Searson, J. Electrochem. Soc. 146, 1436, (1999).

11.- A.A. Istratov, E.R. Weber, J. Electrochem. Soc. 149, G21, (2002).

12.- F. Ronkel, J. W. Schultze, J. Porous Mat. 7, 11, (2000).

13.- N. Shailesh, R.K. Sharma, S.T. Lakshmikumar, Physica E 28, 264, (2005).

14.- V. Labunov, I. Baranov, V. Bondarenko, Thin Solid Films, 64, 479, (1979).

15.- R.E. Marotti, A. Rondoni, E. Quagliata, E.A. Dalchiele, Phys. Status Solidi B 220, 319, (2000)

16.- T. Hadjersi, N. Gabouze, N. Yamamoto, K. Sakamaki and H. Takai, Thin solid films 459, 249, (2004).

17.- M.A. Vásquez, G. Águila, G. García-Salgado, G. Romero-Paredes, R. Peña-Sierra, Revista Mexicana de Física 53, 431, (2007).

18.- V. Lehmann, S. Rönnebeck, J. Electrochem. Soc. 146, 2968, (1999).

19.- X. G. Zhang, S. D. Collins, and R. L. Smith, J. Electrochem. Soc. 136, 1561, (1989).

20.- W. Rivera, C. Torres, A. Pisso, Revista Colombiana de Física 34, 82, (2002).

21.- J.O'M. Bockris, A.K.N. Reddy, M. Gamboa-Adelco, Modern Electrochemistry 2A, Fundamentals of electrodics, second edition, KA/ PP, New York, 2000. 